\title{
Al ethics: A framework for measuring embodied carbon in Al systems
}

\author{
Catherine Mulligan $^{1}$ (D) Silvia Elaluf-Calderwood ${ }^{2}$
}

Received: 4 May 2021 / Accepted: 8 June 2021 / Published online: 21 June 2021

(c) The Author(s) 2021

\begin{abstract}
This paper outlines the ethical implications of AI from a climate perspective. So far, much of the discussion around AI ethics have focused on bias, unexplainable outcomes, privacy and other social impacts of such systems. The role and contribution of AI towards climate change and the ethical implications of its contribution to an unjust distribution of impact on the planet, humans and flora and fauna have not yet been covered in detail within the technical community. Within this paper, we aim to raise some of the issues of AI associated with climate justice and we propose a framework that will allow the AI and ICT industries to measure their true impact on the planet, propose an organisational structure to take this work forward and propose future research areas for this important topic.
\end{abstract}

Keywords Sustainability $\cdot$ Embodied carbon $\cdot$ AI $\cdot$ Climate change $\cdot$ Ethics

\section{Introduction}

The significant majority of work around AI ethics has so far been focussed on a limited problem set of issues. This is because AI ethics has "largely emerged as a response to the range of individual and societal harms that the misuse, abuse, poor design, or negative unintended consequences of AI systems may cause" [1]. These are extremely important issues and can be summarised around a few areas:

- Bias and discrimination, where AI reinforces existing structural issues in society along racial, socio-economic, gender or other lines.

- Denial of individual autonomy, recourse, and rights, where responsibility for the decisions taken by AI makes it extremely difficult to pinpoint responsibility.

- Non-transparent, unexplainable, or unjustifiable outcomes, where algorithms produce results that affect peoples' lives that are unclear or not easily explained to the end-user and sometimes even the system designer.

- Invasions of privacy, where the extractive nature of data collection to fuel AI is itself responsible for caus-

Catherine Mulligan

catherine.mulligan@ tecnico.ulisboa.pt

1 DEI / IST - Universidade de Lisboa, Lisbon, Portugal

2 ISA/BS, Florida International University, Miami, FL, USA ing infractions of privacy. Alternatively, the role that AI systems play in nudging people can be privacy invasive.

- Isolation and disintegration of social connection, where an increased reliance on AI systems decreases the requirement for face-to-face interactions creating a more disintegrated social life.

- Unreliable, unsafe, or poor-quality outcomes, poor design practices can lead to unreliable products.

One aspect of AI ethics that has not been as strongly assessed, however, is its overall climate impact [2, 3], i.e., its impact on the planet and the role that it has in contributing to climate change. The significant majority of the discussions focus rather on its positive effects on measuring or improving humanities response to climate change $[4,5]$. As a result, the impact that AI has from a climate justice perspective are also not widely discussed the fact that the beneficiaries of AI are mainly based in the so-called developed nations while the lower GDP countries will increasingly face the burdens of dealing with the environmental impact of AI; initial work in this space has been done related to e.g., impacts of the semiconductor industry [6-9], but there is no assessment of the justice aspects of destroying the environment in Malaysia for the benefit of users in the USA, Europe, Oceania and elsewhere in Asia.

This paper, therefore, assesses AI systems from the ethical perspective of climate change and compares the approach the ICT industry is taking with another high climate impact 
industry - construction. Finally, it proposes a framework to properly measure the overall impacts of AI from this viewpoint and provides recommendations about how the framework should be implemented within the ICT industry. We consider proposing a unified measurement framework for climate impact of ICT as a critical aspect to include in ethical discussions around AI. Without correct measurements and unified frameworks, it will be impossible for the ICT industry to assess how it will manage and mitigate its role in dramatic climate change across all industries and all human activity.

\section{Climate change and climate emergency}

To understand the impact of AI on the climate change agenda, we must first understand the overall impact of climate change itself. This section provides a brief review of climate change and the necessity for action by all industries.

In its landmark report in 2018 [10], the IPCC outlined possible scenarios associated with increases in average global temperatures between 1.5 and 2 degrees C. Despite demands for action to ensure that the earth does not exceed these temperatures, each year it seems that new records are set-2019 was 1.1 degrees higher than pre-industrial temperatures [11] and saw new records for bushfires in Australia and the USA that were deemed to be the result of cascade effects of climate change [12]. The IPCC report predicts an overall increased frequency and magnitude of extreme weather events from heatwaves, droughts, flooding, winter storms, hurricanes as a result of increased average global temperatures [10]. Further research has set out the current and predicted impacts of our current climate trajectory:

- 30 per cent of the world's population is exposed to deadly heat waves more than 20 days a year [13] and 2019 was the second hottest year on record [11].

- Average temperatures for the 5-year (2015-2019) and 10-year (2010-2019) periods are the highest on record [11]

- In 2019, total greenhouse gas emissions, including landuse change, reached a new high of 59.1 gigatonnes of carbon dioxide equivalent (GtCO2e) [14]

- Based on today's insufficient global commitments to reduce climate polluting emissions, a rebound in greenhouse gases from a return to high-carbon societies after the pandemic may push 2030 emissions even higher-up to $60 \mathrm{GtCO} 2 \mathrm{e}$ [14].

A catastrophic breakdown of climate is likely to result in entire eco-systems being destroyed with the consequences being in some cases irreversible [10]. Death and disease are predicted to increase dramatically as global warming increases $[10,15]$, illustrating that climate change may compromise rights to life, liberty and personal security all of which hold a profound set of ethical implications.

It is becoming increasingly clear, therefore, that we can no longer afford to ignore the climate impacts of the systems and solutions that we build. We are facing a climate emergency and despite many statements and promises by governments and corporations worldwide, concerted and co-ordinated action is still lacking at the levels required to ensure our world is liveable; all industries, all consumers and all governments must act together to end climate change, this process must start with an honest assessment of the true impact any particular industry has.

\section{Environmental ethics and climate justice}

Environmental ethics draws from existing ethical literature; there are strong links for example to the concepts of utilitarianism [16, 17] deontology [18] and care [19]. A critical aspect is the notion of care in particular with its application to understanding our impact-and, therefore, responsibilities towards-current and future generations that will be impacted by our actions today. Jeremy Bentham's utilitarianism is based on maximizing the good for the most people over the longest time, and he further stated that we all tend to value near-term, future benefits more than those in the more distant future; this has often been the approach taken in climate discussions-asking people to think about their children and their grandchildren and what type of planet they will be leaving them-i.e., distributive justice.

A key issue that until recently has often been overlooked in the discussions about climate ethics, however, is the distribution of the impacts of climate change across the world today. The impacts of climate change are increasingly recognised as being unevenly distributed across the globewith people who are benefitting least from the consumption often paying the highest price in terms of climate change. A fundamental question-namely when do individual rights need to take a back seat compared to the overall rights of the planet and other creatures and indeed future generations emerges as a result of analysing climate issues through the lens of utilitarianism, deontology and care. Indeed, some attempts to manage these contradictions have been made by e.g., Sagoff [20], who suggests that "ethics of care" should have value, love, and caring for other people and non-human life. Irrespective of the ethical framework taken, the order and magnitude of the climate question renders the moral need to act.

Another ethical perspective that can be taken is that of (political) justice-what is the just use of resources and distribution of wealth, risks and impacts? Hayward [21] 
illustrates four main approaches from ethical literature and climate change that we can usefully draw from:

1. Responsibilities i.e., of individuals, organisations, governments etc.

2. Links between Human Rights and climate change i.e., how climate change impacts the dignity of humans with respect to their safety, access to amenities, education, etc.

3. Justice in the present versus justice in the future i.e., the ethical questions regarding the rights of future generations to derive value and live well on earth.

4. Relation between individual and collective responsibilities i.e., questions regarding the liberty of an individual in contexts when that liberty has devastating consequences to the environment, whether action can meaningfully be taken at an individual level or through nation (industrial strategy), etc.

The previous focus for the technical community around AI ethics has been technology deterministic-i.e., the focus has often been an immediate development of a technical solution to ethical problems. For example, rather than taking a step back and assessing the overall ethical implications of AI, what has emerged are a number of frameworks that ensure that AI is used "safely", "ethically" and "don't have bias" etc.... Other approaches have instead applied more technology to solve these ethical issues-through the development of algorithms and statistical analysis methods to prevent the inclusion of biased data. These approaches are in themselves fraught with inherently ethical dilemmasnamely who's ethics are we talking about? What is ethical? Who decides what an ethical algorithm looks like? Who and how to enforce these? All of these ethical issues are also present in any discussion about AI and its impact on the climate-and it is ethics itself that can help us provide clarity and order to our ideas both about climate change Hayward [21] and about AI's impact on climate. In fact, AI has entered the climate change debate as a possible solution-where recently proposed legislation on AI by the EU talks about utilizing AI for climate modelling without discussing the environmental impact of AI [22].

A final perspective around environmental ethics-in particular when it comes to AI and climate justice-are the non-Western-centric perspectives and their inclusion in the discussions regarding both the social impacts of $\mathrm{AI}$ and the environmental impacts. AI in particular is resource intensive and the vast majority of AI ethics frameworks have come from China, UK, EU and the United States. These frameworks can run the risk of ignoring the social, legal and ethical landscapes of non-Western and lower GDP economies across the world. In particular from an environmental and climate justice perspective, ignoring these perspectives can at best lead to a perpetuation of western ideals that have previously not ensured best possible outcomes for all nations and people in the world and at worst appear as patronising and neo-colonialization using digital technologies. Concepts such as Ubuntu [23] and learning-based transformations towards sustainability inspired by Humberto Maturana and Paulo Freire [24] in Latin America have as much to offer the ethics of AI discussions and the frameworks that can be developed to help manage them [25, $26]$ as any western framework. In particular, their approach to creating common ground and common understanding around different contexts is a critical benefit.

With regards to climate justice, however, there is an extra incentive to adopt and integrate the non-Western frameworks, perspectives and ethics-namely that such knowledge can assist in the mitigation of the effects of climate change itself. In fact, there is much to be said that Western perspectives and frameworks could be expanded by more detailed collaboration with traditional and indigenous ethical frameworks [27]; traditional ethics can teach us much about how to live in difficult environments and deal with radical change. As an example, the Northern Territory Australian Aborignals Karparti Ecology could be applied to the global discussions around the impact of AI:

"The term karparti is based on the Kriol word for the English expression 'cup of tea'...The phrase 'karparti' is used here as an analogy for an unhurried and respectful approach to discussions or research with senior custodians of knowledge on mutually beneficial terms" [28]

Such systems of ethics have survived millennia exactly because they can be used to successfully navigate complex systems of change, so much so that a "sea change" should be sought [28] in how we approach environmental discussionsand the inclusion of non-Western perspectives is critical to ensuring the ability of discussions around AI ethics to have any genuine impact on the world.

In summary, the climate emergency therefore calls for urgent action to radically transform current unsustainable models of consumption; such transformations cannot be left to the consumers alone to become "green", "conscious" or other similar phrases that are often used within corporate circles but need to be delivered by industries themselves. Industries need to take responsibility for the climate impact their solutions have and take the steps required to mitigate the impact of them. To assist the AI industry, take the concrete steps required, we have developed a framework for measuring AI impact on climate. 


\section{Existing approaches to climate change within the ICT industry}

It is interesting that in the middle of a climate emergency, the significant majority of discussions around technology and its impact on climate change are positive; namely they are aimed at the discussion about how technology is going to help us cope with climate change [29]. The United States in particular seem to place a significant amount of faith in technology and innovation to help solve the climate crisis, rather than to change the behaviour of industries and citizens [30]. The EU also seems to be taking an innovation drive but are also working to ensure that changes in behaviour across industry and citizenry are implemented [31].

This rhetoric is repeated within the ICT industry itself in a more global fashion; the significant majority of statements about ICT and climate change are positive-illustrating use of data or new technologies including AI will help "solve some of the world's most intractable problems"; a phrase that seems to be repeated so often as to have become a mantra for the industry. This indeed may be true, but what is missing is a depth of understanding about the actual overall climate impact of the ICT and AI industries themselves and a unified method of measurement.

Climate change itself has naturally not gone unnoticed by some of the largest proponents of AI-recent announcements across the ICT industry can read as though they are the heart and soul of responding to the climate emergency. Below is a summary of the pledges made by four of the largest AI producers in the world during 2021 alone:

\subsection{Amazon}

Amazon's Climate Pledge has 105 signatory companies agreeing to achieve net-zero emissions by 2040 . They have committed \$2 billion to invest into technologies that slow climate change [31].

\subsection{Google}

Google has a goal to operate 24/7 on carbon-free energy by 2030 while already running their operations $100 \%$ on renewable energy; have commissioned $\$ 4$ billion to purchase clean energy from 50+ wind and solar projects through 2034 [32].

\subsection{Apple}

Apple has ambitious goals to become carbon neutral across its entire value chain by $2030-20$ years sooner than IPCC targets. With the launch of the 'Restore Fund', Apple along with Goldman Sachs and NGO, 'Conversation International' has commissioned a $\$ 200$ million investment fund to promote sustainable forestry [33].

\subsection{Microsoft}

Microsoft promises to be 'carbon-negative' by 2030 and remove their historical carbon emissions by 2050 . Their climate innovation fund will fund $\$ 1$ billion over the next 4 years towards new technologies that help fight climate change [34].

While these commitments are commendable, one of the biggest issues associated with them is the fact that there is no unified method for measuring the impact of the AI industries moving to be "carbon neutral" or "carbon negative"-as a result many of these commitments may be unmeasurable or left to self-measurement. More importantly, there is a distinct lack of clarity of what it means to remove historical carbon emissions - and little information is provided for these types of claims except "all the carbon the company has emitted either directly or by electrical consumption since it was founded in 1975" [34] in Microsoft's case. Despite the bold claims, therefore, they are likely to fall significantly below the necessary actions to ensure that the world meets its climate targets. It will also prove difficult for companies to be held to account.

Moreover, from a global perspective there has been little unified cross-sector approaches to ensuring the measurement of ICT systems can be addressed. While some of approaches are useful to manage and mitigate some of the impacts of ICT on climate, there is currently no real framework that provides a unified perspective on climate change impact of ICT-as a result, there is little opportunity for a crossindustry approach to ensuring ICT meets its climate targets and promises.

As an example, the International Telecommunications Union (ITU) acts as the main normative standards development agency for the global ICT industry. The ITU has worked on "green ICT standards" and produced 117 standards, recommendations and supplements since 2011 [35]; we have summarised the main standards and supplements produced between 2019 and 2021 in Table 1 . As can be seen in Table 1, much of the work in the ICT industry has focussed on the type of energy used to fuel the systems in placenamely the operational carbon production. ICT companies have so far, therefore, been able to claim green status by solely promising to move towards renewable energy sources for their networks and systems, more commonly referred to as operational carbon emissions-i.e., carbon emissions released through the energy/electricity consumed running a system. As will be discussed in subsequent sections, operational energy consumption in only one very small aspect of carbon emissions in the ICT industry-and a total system 


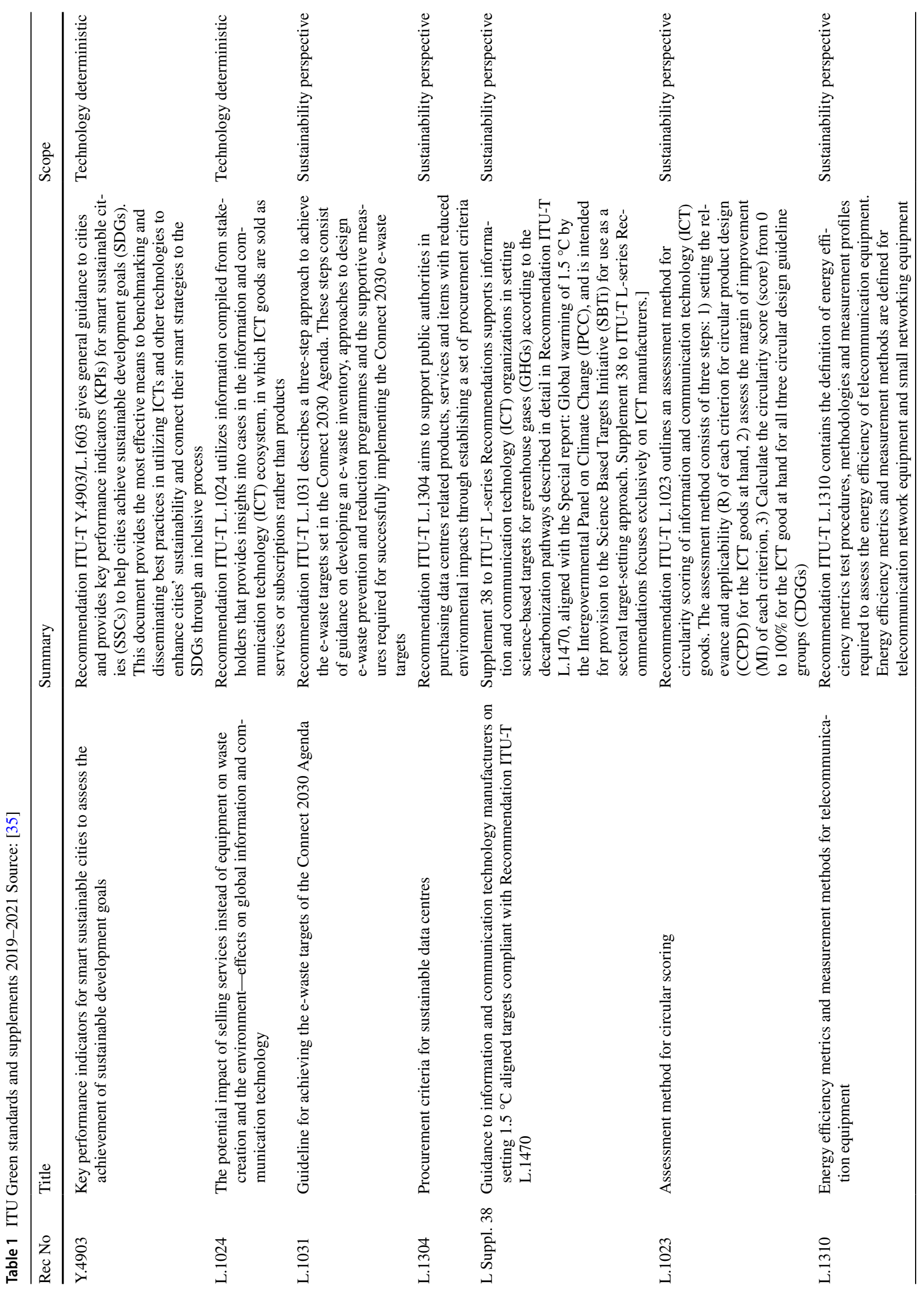




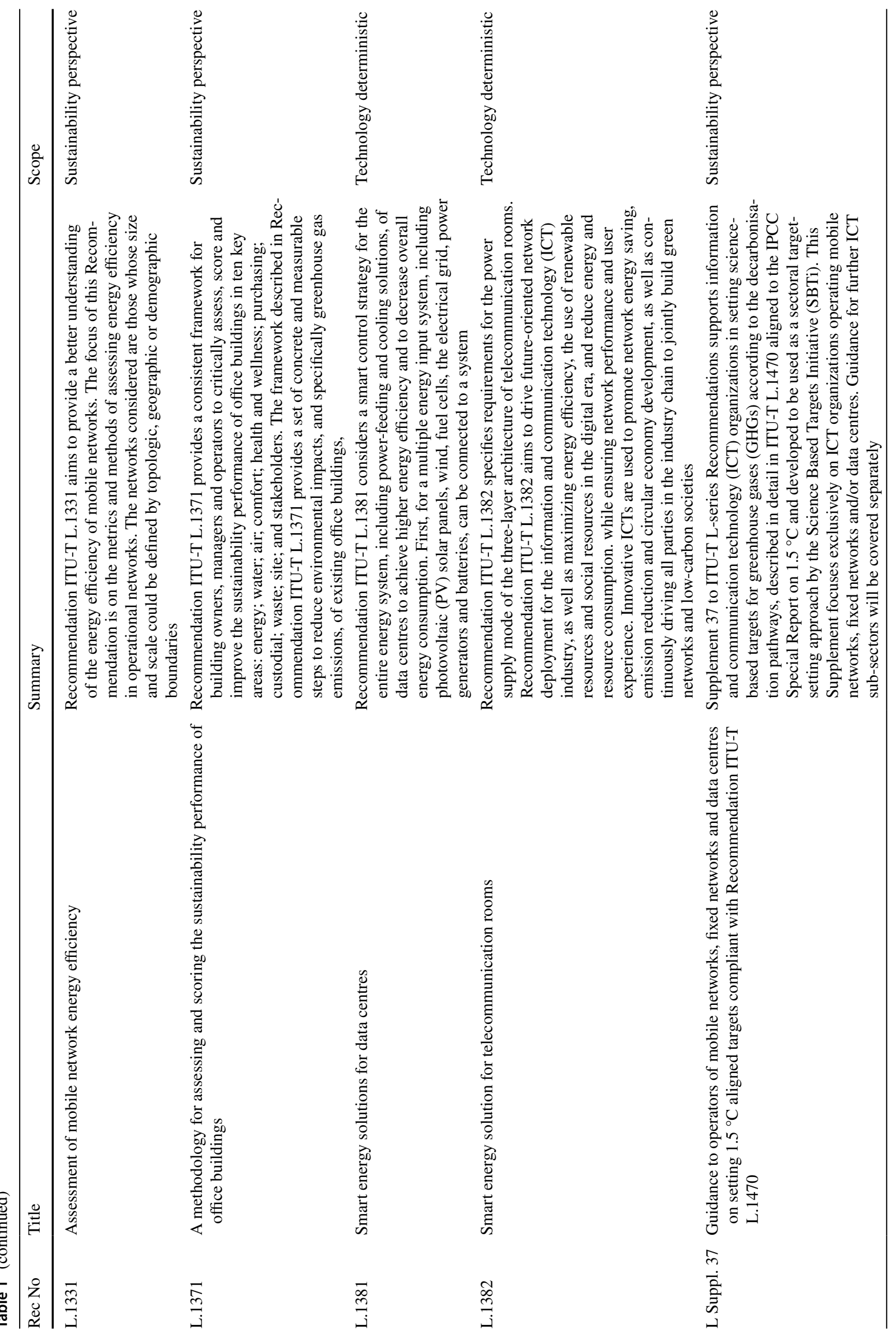


view of embodied carbon is required to ensure that the industry is able to measure and achieve its goals effectively.

Our review of these standards reveals two main typesones that are Technology Deterministic and those that are taking a Sustainability Perspective:

Technology deterministic standards are those that are about technology creating positive impacts on the climatefor example using ICT for smart cities or for energy efficiency improvements. These standards or recommendations mainly take into account the operational energy or carbon emissions of a system or component of a system.

Sustainability perspective standards are those that attempt to manage/mitigate the role of ICT in the creation of environmental damage - at first glance many of these types of standards may seem to address the issues of sustainability in the ICT industry, however, all of these standards focus on small aspects of the industry-e.g., mobile devices or data centres rather than providing a systems perspective. These standards, therefore, do not provide a broad enough spectrum to allow for analysis of any entire ICT solution-as a result the total impact of the ICT industry remains uncaptured in this regard.

Other industries have provided their constituents with uniform and cross-industry frameworks and standards to ensure that the entirety of the carbon emissions produced by a system are fully accounted for and can be actively understood and mitigated. One example is the construction industry - we turn our attention now to their approach to see if we can apply similar frameworks into the ICT industry; the structured work by the ITU could act as partial building blocks in an entire industry/system perspective for measuring the environmental impact of the industry. In addition, due to the standardised component nature of the ICT industry itself, it lends itself readily to pre-compiled sets of data for environmental impact assessment.

\section{Other industry approaches to climate change}

As discussed, the ICT sector is lagging behind for participating in initiatives to address climate change. There is a lack of unified vision on what the goals and benchmarks will be as well as independent assessments where the industry collaborates and participates. Other industries have taken a very different approach to the issue of climate change, for example the construction industry. The role of construction and its large impact on climate is well-documented and understood, e.g., the built environment contributes around $40 \%$ of the UK's total carbon footprint [36]. As a result, many initiatives have been developed over the years to assess, measure and mitigate its impact. 
One such approach that the construction industry took was through a cross industry effort to measure not just operational carbon, but embodied carbon. Embodied carbon relates to those emissions that are associated with materials and construction processes throughout the whole lifecycle of a building or infrastructure. This includes the carbon used for the extraction of component resources, as well as the design, construction phases. In addition, embodied carbon relates to the use aspects that are not covered by operational energy consumption - within construction these types of carbon emissions are often associated with the chemical reactions that cause $\mathrm{CO} 2$ emissions from concrete as the building [37].

The result was a standard EN 15978 more commonly referred to as the Carbon Hierarchy Framework, which sets out methods for the industry to measure not just operational carbon, but also the embodied carbon in the manufacture, construction, use and demolition of buildings. Through using this framework, a co-ordinated effort across the entire construction industry in approaching "Net Zero" - or achieving a balance where the amount we add is no more than the amount taken away-becomes possible and achievable. Through promoting holistic thinking about the carbon impact unintended consequences are surfaced, properly dealt with and therefore become more avoidable. It contains not just the operational impacts of a building, but the entire lifecycle impact of a building from design, manufacture and all the way through the decommissioning. An important part of this is about the embodied carbon-the carbon that is the resultant emissions from all the activities involved in the creation and demolition of a building [38].

The carbon hierarchy framework is split into five phases-four which are active parts of the system boundary associated with the building and one that is external to the system boundary of the building in question. Briefly, the first four phases are: cover "Carbon emissions associated with materials and construction processes throughout the whole lifecycle of a building or infrastructure" [38] — as a result embodied carbon includes:

1. Production phase: material extraction, transport to manufacturer, manufacturing.

2. Installation/construction phase: transport of equipment to customer or site, construction.

3. Use phase: use (e.g., concrete carbonation), maintenance, repair, replacement, refurbishment.

4. End-of-life phase: deconstruction, transport to end of life facilities, processing, disposal.

5. Beyond the lifecycle phase: "Carbon emissions or emissions savings incurred due to reuse or recycling of materials or emissions avoided due to using waste as a fuel source for another process. This is key for maximising resource efficient uses of materials at the end of life." [38]

The structured approach to building and implementing an ICT system is not that dissimilar to the creation of infrastructure such as a building - many of the processes may be considered similar. In fact, the ICT industry often takes phrases from the built environment for that exact reason-software and systems architecture, Systems Design and Engineering, Refactoring, etc. all evoke areas of construction. In particular large-scale systems that rely on data centres, cloud computing, mobile networks and other similarly dimensioned systems can usefully learn from the construction industry in terms of measurement of both operational and embodied carbon; in particular the definitions used in the EN 15978 are of interest. We discuss these in the next section.

\section{$6 \mathrm{Al}$ and the climate emergency}

Within this paper, we focus on one specific area of technology to understand the true impacts of digital technologies on the climate emergency and the associated ethics of climate and environmental justice-AI. We have taken inspiration from the work in the construction industry to assess and surface the entire concept of embodied carbon. As operational carbon becomes effectively managed, embodied carbon becomes more important in ensuring that we are actively working to reduce our emissions. Through a strong focus on operational carbon emissions, the ICT industry has been able to claim mainly that they contribute positively to the overall environmental emergency by claiming that the ICT industry ensures efficiency, capturing and analysing data in new ways to help us understand the climate changes facing us more effectively. This has been possible as the technology industry has largely ignored the full impact of its supply chains across the world.

Because AI and machine learning systems organically improve with the enlargement of access to data and the growth of computing power and it "may not be long before AI technologies become gatekeepers for the advancement of vital public interests and sustainable human development" [1], their increasing use means increasing use of both precious, non-renewable and rare natural resources as well as dwindling carbon budgets; AI systems are power intensive and semiconductor hungry systems. Without drastic changes to the way this sector operates, this growth will consume vast amounts of our available natural resources. Measuring the entire life cycle of carbon across its entire supply chain is, therefore, critical for society to be able to make robust choices about where and when it applies these technologies.

In the same way as the construction industry, carbon emissions associated with ICT are released not only during 
the operational life, but during the manufacturing, transportation, construction and end of life phases of digital infrastructure. These type of emissions, or embodied carbon, have been overlooked but contribute large amounts of carbon. In the construction industry about $11 \%$ of global emissions are caused by embodied carbon [38]. If a true representation of the carbon emissions of an AI system is to be assessed therefore, the upfront carbon-or those emissions that are released prior to the system being used are critical to assess as it will consume large parts of the world's carbon budget. AI systems are heavily dependent on hardware-specifically semiconductors. Research by consulting company McKinsey illustrates an 18\% increase in the sales of semiconductors associated with AI than for non-AI semiconductors [39]. While the current focus of the ICT industry has been on operational carbon, namely the type of energy used to run a digital infrastructure once it is built, significant amounts of carbon go into the design, material extraction, building and installation of the system - these types of carbon now have a high level of importance as a proportion of total emissions; as a result we need to measure these as well as the operational carbon to ensure that efforts to mitigate and control climate change are focussed on the correct actions.

The supply chain of AI is illustrated briefly below:

As can be seen, the ICT industry has focussed mainly on measuring the operational carbon of the final systema very small part of the entire supply chain. Figure 1 also illustrates the embodied carbon that is currently unmeasured, this includes but is not limited to:

1. Semiconductors: mining, mineral extraction and water impacts.

2. Sub-component manufacture: mining, rare mineral extraction, water impacts, plastic consumption for casings.

3. Technology vendors: mining, rare mineral extraction, water impacts, plastics for casings
4. System integration: design, installation and plastics for casings.

\section{Suggested solution}

Our brief review illustrates that in comparison to the construction industry, the technology industry is poorly organised in comparison when it comes to net zero goals. There are a few standards that are around, some are in development that relate to ICT and the "green" agenda-but none that provide the methods to measure the embodied carbon within technology systems from a holistic systems-thinking perspective. If the technology industry is unable to take similarly robust approaches to assessing not just carbon impact but the environmental impact of digital technologies, then the technology deterministic approaches are doomed to failure—and indeed may just make things worse.

Taking the construction industry as inspiration, we have, therefore, adapted the EN 15,978 standard to outline an initial framework that captures the embodied carbon hierarchy within the technology industry. Instead of a building, our unit of analysis becomes a Technical System - the entirety of the system in question from the design phase, the product development phase (for each of the components of the system in question), any new buildings or masts that are built for the infrastructure, as well as the operational and eventual sunsetting of the system.

To understand the real embodied carbon of a technology system, however, we need to also think through the construction of a system - this includes the mining performed to extract minerals and other precious metals to build the chipsets that comprise the system.

An initial overview framework could look as per Fig. 2:

The significant majority of existing analyses focus on operational carbon and therefore on only one part of the entire carbon hierarchy. Such analyses rely on ensuring that systems are using renewable energy sources or

Embodied Carbon: Currently unmeasured by ICT industry

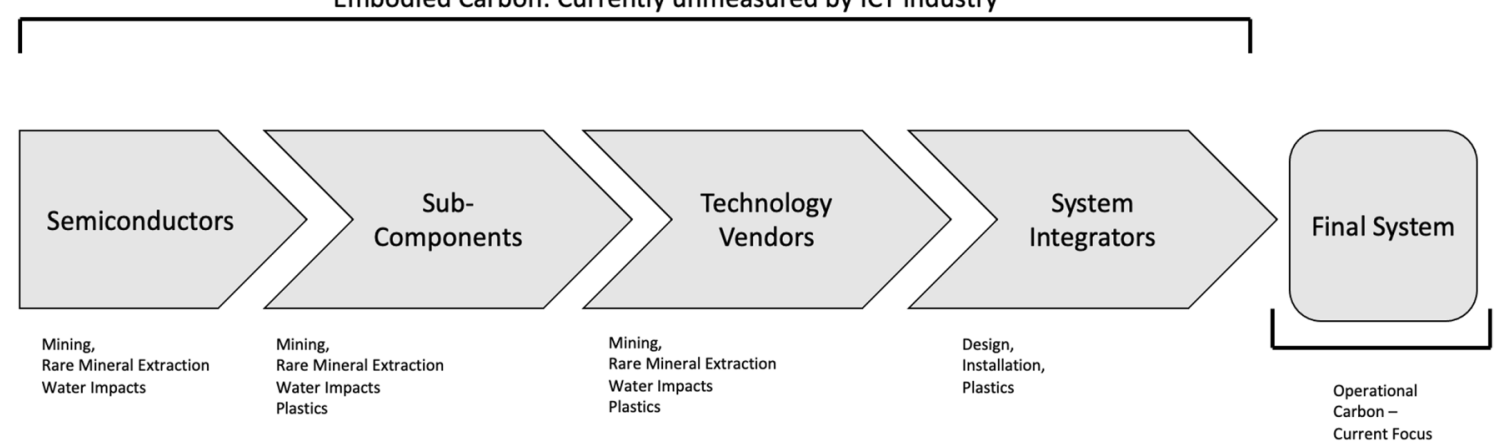

Fig. 1 Simplified supply chain of AI adapted from [39] 


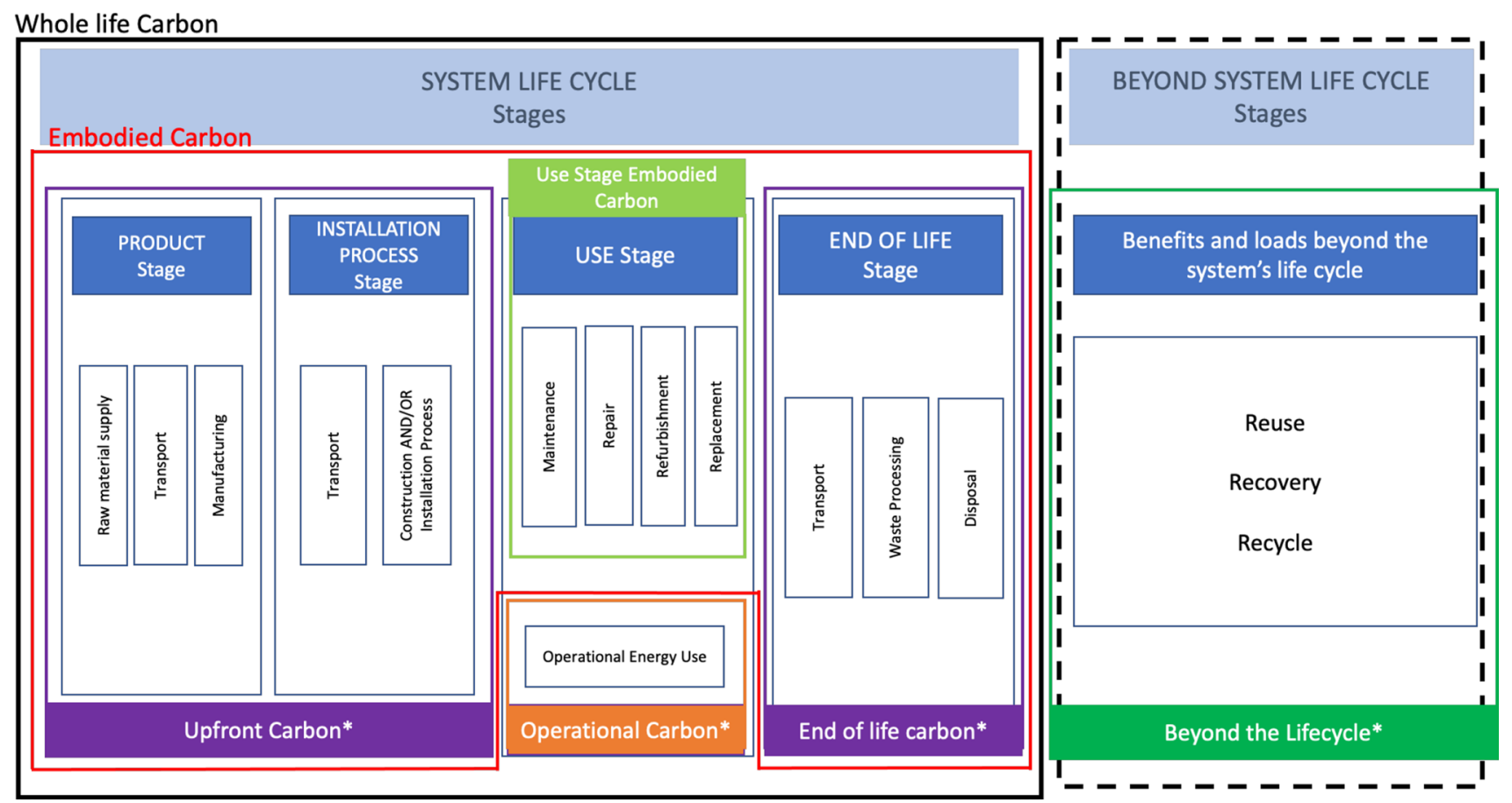

Fig. 2 Embodied carbon measurement framework for ICT (adapted from EN 15978 to AI supply chain)

similar improvements. As can be seen in Fig. 1, however, there is a far broader area of carbon that needs to be assessed and addressed in the entire lifecycle of ICT systems.

\section{System life cycle}

To understand the carbon impact of a technology solution, we adapt the work from EN 15978 embodied carbon includes.

1. A production phase: material extraction, transport to manufacturer, manufacturing.

2. An installation/construction phase: transport of equipment to customer or site, construction (if required for e.g., mobile base stations).

3. A use phase: maintenance, repair, replacement, refurbishment.

4. An end-of-life phase: deconstruction, transport to end of life facilities, processing, disposal.

5. Finally, we need to capture impacts external to the system boundary-these are often positive impacts where components can be re-used, so there is a:

Beyond the lifecycle Phase: Carbon emissions or emissions savings incurred due to reuse or recycling of materials or emissions avoided due to using waste as a fuel source for another process.

\section{Suggested implementation}

A key issue around the development of such a framework would be who could lead it? The efforts would need to be cross-industry and developed in a similar fashion to the EN 15978 standard. It would require input from industry, government and other stakeholders to ensure that the ambitious goals for climate change in the ICT industry; the urgency of the climate change we are undergoing should mean that this is completed within two years. Several routes to develop this could therefore emerge:

- Regional work starts as was done for EN 15978, which started as a BSI standard in the UK

- An open call is developed across the EU to co-develop this across all stakeholders

- Through this work, a new European Standard could be developed along the lines of EN 15978 for the ICT industry

- The ITU could work to expand the standard and have it ratified at a global level 
There ought to be an open and transparent discussion between the EU and the ICT industry and general public on the impact, effectiveness and measurement of this standard for the common benefit.

\section{Future work}

This paper has assessed concerns associated with GHG emissions and outlined some initial steps to a unified framework that can assist the ICT industry properly assess and implement its ambitious goals to assist with climate change. The framework is designed to understand the climate justice implications of use of AI across the globe and outlines a suggested global cross-industry effort to measure and mitigate the impact of ICT. Such an initiative could go some way to ensure AI is ethical and appropriately developed.

GHG emissions are really only one part of the story, however. In addition to GHG and embodied carbon, the ICT industry could usefully assess other aspects of climate justice in the development of its systems, and we propose that our framework could be expanded to include these aspects. Other areas include adverse impacts on the environment from semiconductor manufacture-including groundwater and air pollution and generating toxic waste as a by-product of the semiconductor manufacturing process. For example, "fabricating a small $2 \mathrm{~g}$ microchip requires $32 \mathrm{~kg}$ of ware, $1.6 \mathrm{~kg}$ of petroleum and $72 \mathrm{~g}$ of chemicals. If we multiple those values by the millions of chips manufactured in just one factory each year, the result will serve evidence for large-scale wastage of water along with the generation of toxic chemicals" [40]. Such a framework would prove extremely useful for the entire ICT industry, not just AI. As discussed previously, one key difference between the construction industry and the ICT industry is the requirement to measure carbon carbonation-namely the chemical reactions of concrete between its. One aspect that could be usefully investigated in the ICT industry in a similar line are: abiotic depletion, use of limited and rare materials such as lithium for batteries or other rare earth minerals and metals. Many of these are not finite resources in the world and as such considering abiotic depletion may increase the focus on designing physical elements of ICT for easier recycling to allow precious resources to be recovered.

Future work could, therefore, usefully include a full environmental impact assessment framework for the AI industries-this can in turn help society make more effective decisions about what use cases of $\mathrm{AI}$ are appropriate and where the world can afford to apply these technologies and where it cannot.

\section{Conclusions}

The necessity for the ICT industry to measure its embodied carbon, rather than just its embodied carbon contributions to the carbon emissions is long overdue. A cross industry approach, similar to the one applied in the construction industry is required to ensure that the ICT industry can meet and exceed its ambitious targets. It is also necessary to ensure that industry promises with regards to carbon emissions can be effectively measured in a transparent manner that the world's population can truly understand.

The ICT industry is ideally placed to provide a worldleading example measurement of embodied carbon-mainly due to the use of heavily standardised chipsets, semiconductors and componentry across a large variety of systems - the embodied carbon could therefore be measured collectively, rather than needing to be done for every individual project, making the assessment of climate impacts from ICT systems systematic and user-friendly. In addition, the creation of a standard under the auspices of the European Union standards framework could galvanise industry activity and innovation to dramatically reduce the climate impact of the ICT industry. Further work in this space could be to assess the water impacts of ICT and issues around abiotic depletion.

Acknowledgements Prof Mulligan would like to thank Kirsten Henson for her useful discussions on the topic of embodied carbon

\section{Author contributions N/A.}

Funding This research work has received funding from the European Union's Horizon 2020 research and innovation programme under grant agreement no 952226 .

Availability of data and material N/A.

Code availability N/A.

\section{Declarations}

Conflict of interest Authors have no conflicts of interest.

Ethical approval N/A.

Consent to participate N/A.

Consent for publication We consent to publication of this article.

Open Access This article is licensed under a Creative Commons Attribution 4.0 International License, which permits use, sharing, adaptation, distribution and reproduction in any medium or format, as long as you give appropriate credit to the original author(s) and the source, provide a link to the Creative Commons licence, and indicate if changes were made. The images or other third party material in this article are included in the article's Creative Commons licence, unless indicated otherwise in a credit line to the material. If material is not included in the article's Creative Commons licence and your intended use is not 
permitted by statutory regulation or exceeds the permitted use, you will need to obtain permission directly from the copyright holder. To view a copy of this licence, visit http://creativecommons.org/licenses/by/4.0/.

\section{References}

1. Leslie, D.: Understanding artificial intelligence ethics and safety: A guide for the responsible design and implementation of AI systems in the public sector.Alan. Turing. Institute. (2019). https:// doi.org/10.5281/zenodo.3240529

2. van Wynsberghe, A.: 2021, Sustainable AI: AI for sustainability and the sustainability of AI. AI. Ethics. (2021). https://doi.org/10. 1007/s43681-021-00043-6

3. Coeckelbergh, M.: AI for climate: freedom, justice, and other ethical and political challenges. AI. Ethics. 1, 67-72 (2021). https:// doi.org/10.1007/s43681-020-00007-2

4. Haupt, S., Chapman, W., Adams, S., Kirkwood, C., Hosking, S., Robinson, N., Lerch, S., Subramanian, A.: Towards implementing artificial intelligence post-processing in weather and climate: proposed actions from the Oxford 2019 workshop. Trans. R. Soc. A, Phil (2021). https://doi.org/10.1098/rsta.2020.0091

5. Buchanan, A.H., Honey, B.G.: Energy and carbon dioxide implications of building construction. Energ. Buildings. (1994). https:// doi.org/10.1016/0378-7788(94)90024-8

6. Cooper, T., Fallender, S., Pafumi, J., Dettling, J., Humbert, S., Lessard, L., 2011, "A semiconductor company's examination of its water footprint approach," Proceedings of the 2011 IEEE International Symposium on Sustainable Systems and Technology, doi: https://doi.org/10.1109/ISSST.2011.5936865

7. Mullen, E., Morris, M.A.: Green nanofabrication opportunities in the semiconductor industry: A life cycle perspective. Nanomaterials 11(5), 1085 (2021). https://doi.org/10.3390/nano11051085

8. Frost, K., Hua, I.: Quantifying spatiotemporal impacts of the interaction of water scarcity and water use by the global semiconductor manufacturing industry. Water. Resour. Ind. 22, 100115 (2019). https://doi.org/10.1016/j.wri.2019.100115

9. Müller, D.B., Liu, G., Løvik, A.N., Modaresi, R., Pauliuk, S., Steinhoff, F.S., Bratteb $\emptyset$, H.: Carbon emissions of infrastructure development. Environ. Sci. Technol. 47(20), 11739-11746 (2013). https://doi.org/10.1021/es402618m

10. IPPC 2018 , Global Warming of $1.5^{\circ} \mathrm{C}$, an IPCC special report on the impacts of global warming of $1.5^{\circ} \mathrm{C}$ above pre-industrial levels and related global greenhouse gas emission pathways, in the context of strengthening the global response to the threat of climate change, sustainable development, and efforts to eradicate poverty, available from: https://www.ipcc.ch/sr15/.

11. WMO, 2021, State of the Global Climate 2020, available from: https://public.wmo.int/en/our-mandate/climate/wmo-statementstate-of-global-climate.

12. Kemter, M., Fischer, M., Luna, L.V., Schönfeldt, E., Vogel, J., Banerjee, A., et al.: Cascading hazards in the aftermath of Australia's 2019/2020 Black Summer wildfires. Earth. Future. (2021). https://doi.org/10.1029/2020EF001884

13. UNEP, 2021, Cooling and Climate Change Factsheet, March 2021, available from: https://www.unep.org/resources/factsheet/ cooling-and-climate-change.

14. EGR 2020, UN Environment Program Emissions Gap Report 2020, available from: https://www.unep.org/interactive/emiss ions-gap-report/2020/.

15. Patz, J., Campbell-Lendrum, D., Holloway, T., Foley, J.: Impact of regional climate change on human healther. Nature (2005). https:// doi.org/10.1038/nature04188

16. Bentham, J.: 1780, An Introduction to the Principles of Morals and Legislation. Hafner Publishing Co., New York (1948)
17. Mills, J.S., 1863, Utilitarianism, Hackett Publishing Co, Inc; 2nd edition (1 Mar. 2002) ISBN-10 : 087220605X, 2002

18. Kant, I.: Critique of Pure Reason (M. Weigelt, Trans.). Penguin Classics, London, England (2003)

19. DesJardins, J.R.: Environmental ethics: an introduction to environmental philosophy. Wadsworth, Belmont, Calif (1993)

20. Sagoff, M.: 2004, Price, Principle, and the Environment, 2004, Cambridge. Cambridge University Press, UK (2004)

21. Hayward, T.: Climate change and ethics. Nat. Clim. Chang. (2012). https://doi.org/10.1038/NCLIMATE1615

22. EUCa 2021, Proposal for a Regulation laying down harmonised rules on artificial intelligence (Artificial Intelligence Act), European Commission, available from: https://digital-strategy.ec. europa.eu/en/library/proposal-regulation-laying-down-harmo nised-rules-artificial-intelligence-artificial-intelligence.

23. Gwaravanda E.T. (2019) Ubuntu Environmental Ethics: Conceptions and Misconceptions. In: Chemhuru M. (eds) African Environmental Ethics. The International Library of Environmental, Agricultural and Food Ethics, vol 29. Springer, Cham.

24. Souza, D., Wals, A., Jacobi, P.: Learning-based transformations towards sustainability: a relational approach based on Humberto Maturana and Paulo Freire. Environ. Educ. Res. 25(11), 16051619 (2019). https://doi.org/10.1080/13504622.2019.1641183

25. Mhlambi, S., 2020, "From Rationality to Relationality: Ubuntu as an Ethical and Human Rights Framework for Artificial Intelligence Governance." Carr Center Discussion Paper Series, 2020-009.

26. van Norren, D., Verbeek, P., 2020, The ethics of artificial intelligence through the lens of Ubuntu, Draft-working paper Africa Knows conference 2020 (Africa Study Centre), available from: https://nomadit.co.uk/conference/africaknows/paper/57969.

27. Terblanché-Greeff A.C., 2019, Ubuntu and Environmental Ethics: The West Can Learn from Africa When Faced with Climate Change. In: Chemhuru M. (eds) African Environmental Ethics. The International Library of Environmental, Agricultural and Food Ethics, vol 29. Springer, Cham.

28. Horstman, M., Wightman, G.: Karparti ecology: Recognition of Aboriginal ecological knowledge and its application to management in north-western Australia. Ecol. Manag. Restor. 2(2001), 99-109 (2001)

29. WH 2021, Executive Order on Tackling the Climate Crisis at Home and Abroad, available from: https://www.whitehouse.gov/ briefing-room/presidential-actions/2021/01/27/executive-orderon-tackling-the-climate-crisis-at-home-and-abroad/.

30. EUCb, 2021, 2030 Climate Target Plan, available from: https:// ec.europa.eu/clima/policies/eu-climate-action/2030_ctp_en.

31. Amazon 2021, The Climate Pledge, available from: https://susta inability.aboutamazon.com/about/the-climate-pledge.

32. Google 2021, Our third decade of climate action: Realizing a carbon-free future, available from: https://blog.google/outreachinitiatives/sustainability/our-third-decade-climate-action-reali zing-carbon-free-future/.

33. Apple 2021, Apple and partners launch first-ever $\$ 200$ million Restore Fund to accelerate natural solutions to climate change, available from: https://www.apple.com/uk/newsroom/2021/04/ apple-and-partners-launch-first-ever-200-million-restore-fund/.

34. Microsoft 2020, Microsoft will be carbon negative by 2030, available from: https://blogs.microsoft.com/blog/2020/01/16/micro soft-will-be-carbon-negative-by-2030/.

35. ITU, 2021, 'ITU-T Recommendations'. ITU Access Library. Sustainable Development Goals (blog), 2021. https://www.itu.int/net/ ITU-T/lists/standards.aspx Group $=5 \&$ Domain $=28$.

36. UKGBC, 2021, Climate Change - UKGBC's vision for a sustainable built environment is one that mitigates and adapts to climate change, https://www.ukgbc.org/climate-change/. 
37. Rodrigo, M.N.N., Perera, S., Senaratne, S. and Jin, X., 2019, June. Embodied carbon mitigation strategies in the construction industry. In Proceedings of the CIB World Building Congress, Hong Kong, China (pp. 17-21)

38. WBC, 2019, World Business Council - Bringing embodied carbon upfront: Coordinated action for the building and construction sector to tackle embodied carbon

39. Mulligan, C.: Communications Industry in the Era of Convergence. Routledge (2011)

40. SR, 2020, How can the Semiconductor Industry Achieve Sustainability? Semiconductor Review, Monday October 12th, 2020, available from: https://www.semiconductorreview.com/news/howcan-the-semiconductor-industry-achieve-sustainability--nwid-135. html, retrieved 1st May 2021

Publisher's Note Springer Nature remains neutral with regard to jurisdictional claims in published maps and institutional ailiations. 